УДК $629.33-585$

DOI: 10.36461/NP.2019.52.3.020

\title{
ОБЕСПЕЧЕНИЕ РАЦИОНАЛЬНОГО ТЕМПЕРАТУРНОГО РЕЖИМА КОРОБКИ ПЕРЕДАЧ АВТОМОБИЛЯ КАМАЗ СЕЛЬСКОХОЗЯЙСТВЕННОГО НАЗНАЧЕНИЯ
}

\author{
А. А. Орехов, канд. техн. наук, доцент; С. В. Тимохин, д-р техн. наук, професссор; \\ И. А. Спицын, д-р техн. наук, профрессор; К. З. Кухмазов, д-р техн. наук, профрессор \\ Федеральное государственное бюджетное образовательное учреждение \\ высшего образования «Пензенский государственный аграрный университет», \\ Россия, т. 8 (8412) 62-85-79, e-mail: orehov.aa@pgau.ru
}

В работе рассмотрены особенности эксплуатации автомобилей при низких температурах окружающего воздуха, а также существующие способы и средства тепловой подготовки их агрегатов. Если вопросы тепловой подготовки и поддержания рационального температурного режима двигателей внутреннего сгорания автомобилей в значительной степени решены, то для агрегатов их трансмиссий они требуют дальнейшего развития. Проанализировано применение тепловых аккумуляторов для тепловой подготовки агрегатов автомобилей. Предложен способ и система обеспечения рационального температурного режима коробки передач автомобиля КамАЗ с использованием теплового аккумулятора фазового перехода. Сформулированы цель и задачи исследований. Проведен расчет объема теплоаккумулирующего материала, необходимого для подогрева трансмиссионного масла коробки передач автомобиля КамАЗ до рациональной температуры в условиях зимней эксплуатации. Разработаны гидравлическая и функциональная схемы системы регулирования температуры масла в коробке передач автомобиля КамАЗ с тепловым аккумулятором фазового перехода, применение которой обеспечит быстрый выход на рациональный температурный режим коробки передач автомобиля и его стабилизацию как в зимнее, так и в летнее время года и, тем самым, снизит износ деталей, механические потери в коробке передач, расход топлива автомобилем.

Ключевые слова: тепловая подготовка, агрегат, автомобиль, трансмиссия, коробка передач, температура окружающего воздуха, потери мощности, тепловой аккумулятор фразового перехода, интенсивность изнашивания.

\section{Введение}

При эксплуатации автомобилей их технико-экономические показатели в значительной степени зависят от температурных условий работы их агрегатов, которые, в свою очередь, взаимосвязаны с температурой окружающего воздуха и эксплуатационными режимами их работы (пуск, прогрев, холостой ход, рабочие режимы). Если вопросы тепловой подготовки и поддержания рационального температурного режима двигателей внутреннего сгорания (ДВС) автомобилей в значительной степени решены, то для агрегатов их трансмиссий они требуют дальнейшего развития [3, 9, 16].

Исследования ряда авторов [10, 17, 1921] показывают, что температурный режим агрегатов трансмиссии автомобилей, особенно коробок передач (КП), является одним из основных факторов, влияющих как на потери мощности, так и на интенсивность изнашивания деталей. Наименьшая интенсивность изнашивания деталей КП имеет место при температуре трансмиссионного масла $+70 \ldots 80^{\circ} \mathrm{C}[2,8]$.
Тепловая подготовка агрегатов при безгаражном хранении автомобилей в условиях низких температур окружающего воздуха обеспечивается тремя способами: использованием внешних источников тепла, применением предпусковых подогревателей охлаждающей жидкости и моторного масла, а также сохранением тепла от предыдущей работы ДВС [6].

Известно, что при работе ДВС 60-70 \% энергии, введенной в него с топливом, уходит в атмосферу с выхлопными газами и через систему охлаждения [18]. Тепловая энергия, отводимая охлаждающей жидкостью двигателя, может быть запасена и использована для подогрева трансмиссионного масла в холодное время года. Наиболее эффективно эту задачу можно решить путем использования эффекта фразового перехода некоторых веществ, протекающего при постоянной температуре. Например, плавление и кристаллизация гидроокиси бария происходят при температуре $+78{ }^{\circ} \mathrm{C}$, что позволяет эфффективно использовать выделяющуюся теплоту для 
решения задач тепловой подготовки агрегатов автомобилей. Устройства для использования данного эффректа получили название тепловых аккумуляторов фазового перехода (ТАФП). Целесообразность их применения на автомобилях обусловлена тем, что они способны аккумулировать часть теплоты, содержащейся в охлаждающей жидкости, моторном масле или отработавших газах ДВС, хранить ее в течение достаточно большого периода времени, а затем отдавать элементам агрегатов транспортных машин [4-7, 11-14]. Проведенный патентно-информационный анализ использования ТАФП показал, что их применение для поддержания рационального температурного режима трансмиссионного масла в КП автомобилей изучено не достаточно.

В связи с вышеизложенным, целью настоящей работы является обеспечение рационального температурного режима коробки передач автомобиля КамАЗ на всех эксплуатационных режимах применением системы регулирования температуры масла в коробке передач с использованием теплового аккумулятора фразового перехода.

В соответствие с поставленной целью определены следующие задачи исследований:

- провести расчет объема теплоаккумулирующего материала (ТАМ), необходимого для подогрева трансмиссионного масла КП автомобиля КамАЗ до рациональной температуры в условиях зимней эксплуатации;

- разработать гидравлическую схему системы регулирования температуры масла в КП автомобиля КамАЗ с ТАФП;

- разработать функциональную схему системы регулирования температуры масла в КП автомобиля КамАЗ с ТАФП.

\section{Методы и материалы}

При проведении исследований применялись аналитические методы расчета параметров теплообменных аппаратов с использованием прикладных компьютерных программ.

\section{Результаты}

Для практического использования разрабатываемой системы принципиальным является объем ТАМ, необходимый для подогрева трансмиссионного масла КП автомобиля КамАЗ до требуемой, рациональной температуры в условиях зимней эксплуатации. Определим это количество исходя из уравнения теплового баланса, связывающего количество теплоты $Q_{\mathrm{A}}$, запасенное ТАМ, и количество теплоты, не- обходимого для нагрева корпуса КП $Q_{\text {K }}$ и масла $Q_{\mathrm{M}}$ в ее картере предлагаемой системой с ТАФП, то есть

$$
Q_{\mathrm{A}} \geq Q_{\mathrm{M}}+Q_{\mathrm{K}}, \mathrm{K} \text {. }
$$

Количество теплоты $Q_{\mathrm{A}}$, аккумулируемое ТАМ определяется по формуле [1, 15]

$$
\begin{aligned}
& Q_{A}=\rho_{\pi} \cdot V_{A} \cdot\left[c_{T} \cdot\left(t_{\Pi Л}-t_{1}\right)+r+\right. \\
& \left.+c_{\text {获 }} \cdot\left(t_{2}-t_{\Pi \Omega}\right)\right], \kappa[\%,
\end{aligned}
$$

где $\rho_{ж}$ - плотность ТАМ в жидком состоя-

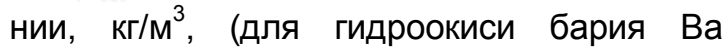
$\left.(\mathrm{OH})_{2} \cdot 8 \mathrm{H}_{2} \mathrm{O}-\rho_{\text {ж }}=2180 \mathrm{\kappa г} / \mathrm{M}^{3}\right)$;

$V_{A}$ - объем теплоаккумулятора, м;

$t_{1}, t_{2}$ - температура ТАМ до и после зарядки, ${ }^{\circ} \mathrm{C}, t_{1}=+78{ }^{\circ} \mathrm{C}, t_{2}=+90{ }^{\circ} \mathrm{C}$;

$t_{\Pi Л}$ - температура плавления ТАМ, ${ }^{\circ} \mathrm{C}$;

$\mathcal{C}_{T}, \mathcal{C}_{\text {ж⿱ }}$ - теплоемкость твердой и жидкой фразы ТАМ, кДж/кг ${ }^{\circ} \mathrm{C}$;

$$
c_{T}=c_{\text {Ж }}=1,17 \text { кДж/кг }{ }^{\circ} \mathrm{C} ;
$$

$\boldsymbol{r}^{*}$ - теплота фазового перехода, кДж/кг;

\section{$\gamma^{*}=267$ кДж/кг.}

Количество теплоты, необходимое для нагрева масла в КП [15]:

$$
Q_{\mathrm{M}}=m_{\mathrm{M}} \cdot c_{\mathrm{M}} \cdot \Delta t_{\mathrm{M}}, \text { кДж, }
$$

где $m_{\mathrm{M}}$ - масса масла, кг, (для КП автомобиля КамАЗ с объемом масла типа ТАП-15 в картере 12 л, $m_{\mathrm{M}}=11,4$ кг);

$\boldsymbol{C}_{\mathrm{M}}$ - теплоемкость масла, кДж/кг ${ }^{\circ} \mathrm{C}$, $\left(C_{\mathrm{M}}=1,7\right.$ кДж/кг $\left.{ }^{\circ} \mathrm{C}\right)$;

$$
\Delta t_{M}=t_{\mathrm{KM}}-t_{\mathrm{HM}},{ }^{\circ} \mathrm{C} \text {, }
$$

где $\Delta t_{M}$ - разница температур конца $t_{\mathrm{KM}}$ и начала $t_{\text {нм }}$ нагрева масла, ${ }^{\circ} \mathrm{C}$;

$$
t_{\mathrm{KM}}=+70{ }^{\circ} \mathrm{C}, t_{\mathrm{HM}}=-15^{\circ} \mathrm{C} \text {. }
$$

При работе предпускового подогревателя охлаждающей жидкости типа 14 ТС, устанавливаемого на все современные модификации автомобилей КамАЗ, происходит некоторый подогрев корпусов агрегатов трансмиссии и находящегося в них масла. При использовании трансмиссионного масла типа ТАП-15 с температурой застывания не выше $-20{ }^{\circ} \mathrm{C}$ работа циркуляционного электронасоса (7) системы подогрева с тепловым аккумулятором (рис. 1) будет возможна при более высокой температуре, поэтому принимаем $t_{\mathrm{HM}}=-15^{\circ} \mathrm{C}$. 


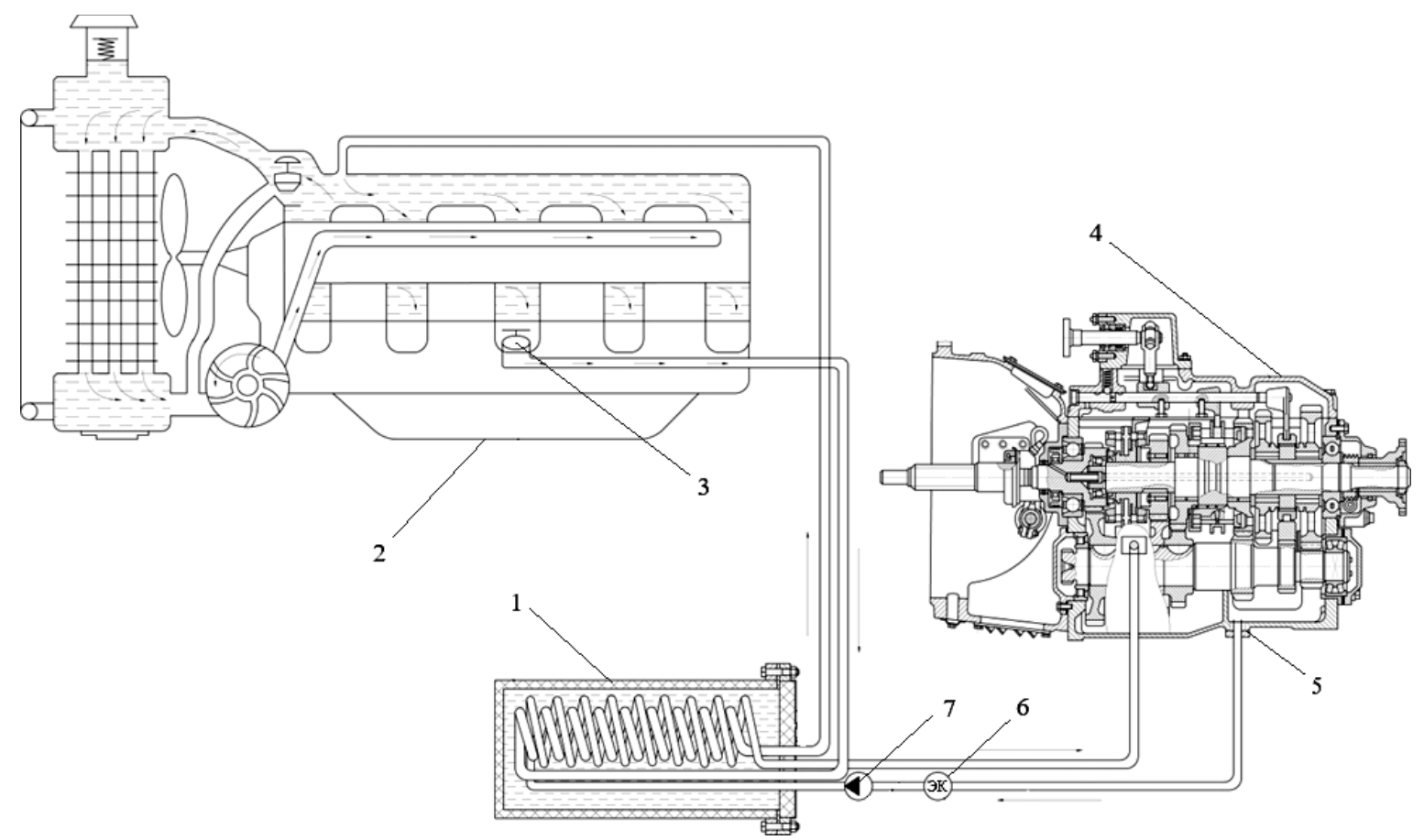

Рис. 1. Гидравлическая схема системы регулирования температуры масла в КП автомобиля КамАЗ с ТАФП:

1 - ТАФП; 2 - ДВС; 3,6 - электромагнитные клапаны; 4- картер коробки передач; 5 - штуцер забора масла из картера КП; 7 - электронасос.

Подогрев масла до этой температуры будет обеспечивать предпусковой подогреватель, а далее до температуры $t_{\mathrm{KM}}=+$ $70{ }^{\circ} \mathrm{C}$ - предлагаемая система с ТАФП по командам датчика температуры масла. Тогда $Q_{\mathrm{M}}=11,4 \cdot 1,7 \cdot(70-(-15))=1647$ кДж.

Количество теплоты, необходимое для нагрева корпуса КП системой подогрева с тепловым аккумулятором [15]:

$$
Q_{\mathrm{K}}=m_{\mathrm{K}}{ }^{*} \mathrm{c}_{\mathrm{q}} \cdot \Delta t_{\mathrm{K}}, \text { кДж, }
$$

где $m_{\kappa}$ - масса корпуса КП и делителя, $\left(m_{\mathrm{K}}=110 \mathrm{\kappa г}\right)$;

$\mathrm{C}_{\mathrm{s}}$ - теплоемкость материала корпуса (для чугуна до $+100{ }^{\circ} \mathrm{C}$

$$
\begin{aligned}
& \left.\mathrm{c}_{\mathrm{q}}=0,54 \text { кДж/кг } \cdot{ }^{\circ} \mathrm{C}\right) ; \\
& \Delta t_{\mathrm{K}}=t_{\mathrm{KK}}-t_{\mathrm{HK},}{ }^{\circ} \mathrm{C},
\end{aligned}
$$

где $\Delta t_{\mathrm{K}}$ - разница температур конца $t_{\mathrm{KK}} n$ начала $t_{\mathrm{Hк}}$ нагрева корпуса $К П,{ }^{\circ} \mathrm{C}$;

$$
\begin{aligned}
& \quad t_{\mathrm{\kappa к}}=+70^{\circ} \mathrm{C}, t_{\mathrm{Hк}}=-15^{\circ} \mathrm{C} . \\
& \quad \text { Тогда } \\
& Q_{\mathrm{K}}=110 \cdot 0,54 \cdot(70-(-15))=5049 \\
& \text { кДж. } \\
& \quad \text { Тогда } Q_{\mathrm{A}} \geq 1647+5049 \geq 6696 \text { кДж. }
\end{aligned}
$$

Объем ТАМ, необходимый для подогрева трансмиссионного масла КП автомобиля КамАЗ до рациональной температуры в условиях зимней эксплуатации выразим из фрормулы (2).

$$
\begin{aligned}
& V_{A}=\frac{Q_{A}}{\rho_{\mathrm{m}} \cdot\left(c_{T} \cdot\left(t_{\mathrm{M}}-t_{1}\right)+r+c_{\mathrm{m}} \cdot\left(t_{2}-t_{\mathrm{M}}\right)\right.}, \mathrm{M}^{2}= \\
& \text { Тогда, с учетом формулы (1): } \\
& V_{A}=\frac{6696}{2180 \cdot(1,17 \cdot(78-78)+267+1,17 \cdot(90-78))}=0,011 \mathrm{M}^{3} \text {. } \\
& \text { Macca TAM ( } \left.m_{\text {TAM }}\right) \text { равна: } \\
& m_{\mathrm{TAM}}=V_{A} \cdot \rho_{\text {w }}, \mathbf{K} \Gamma^{;} \text {; } \\
& m_{\text {TAM }}=0,011 \cdot 2180=23,98 \mathrm{kr} \text {. }
\end{aligned}
$$

На основании проведенных расчетов определены конструктивные параметры теплового аккумулятора и разработаны гидравлическая (рис. 1) и функциональная (рис. 2) схемы системы регулирования температуры масла в КП автомобиля КамАЗ.

Работа системы происходит следующим образом.

При температуре охлаждающей жидкости (ОЖ) в системе охлаждения ДВС (СО ДВС) (рис. 2) выше $+90{ }^{\circ} \mathrm{C}$ по сигналу штатного датчика температуры ОЖ автомобиля (ДТОЖ) включится реле температуры (РТ1), подаст сигнал на первый электромагнитный клапан (ЭК1), который сработает и включит циркуляцию ОЖ через ТАФП, что обеспечит его зарядку (плавле- 


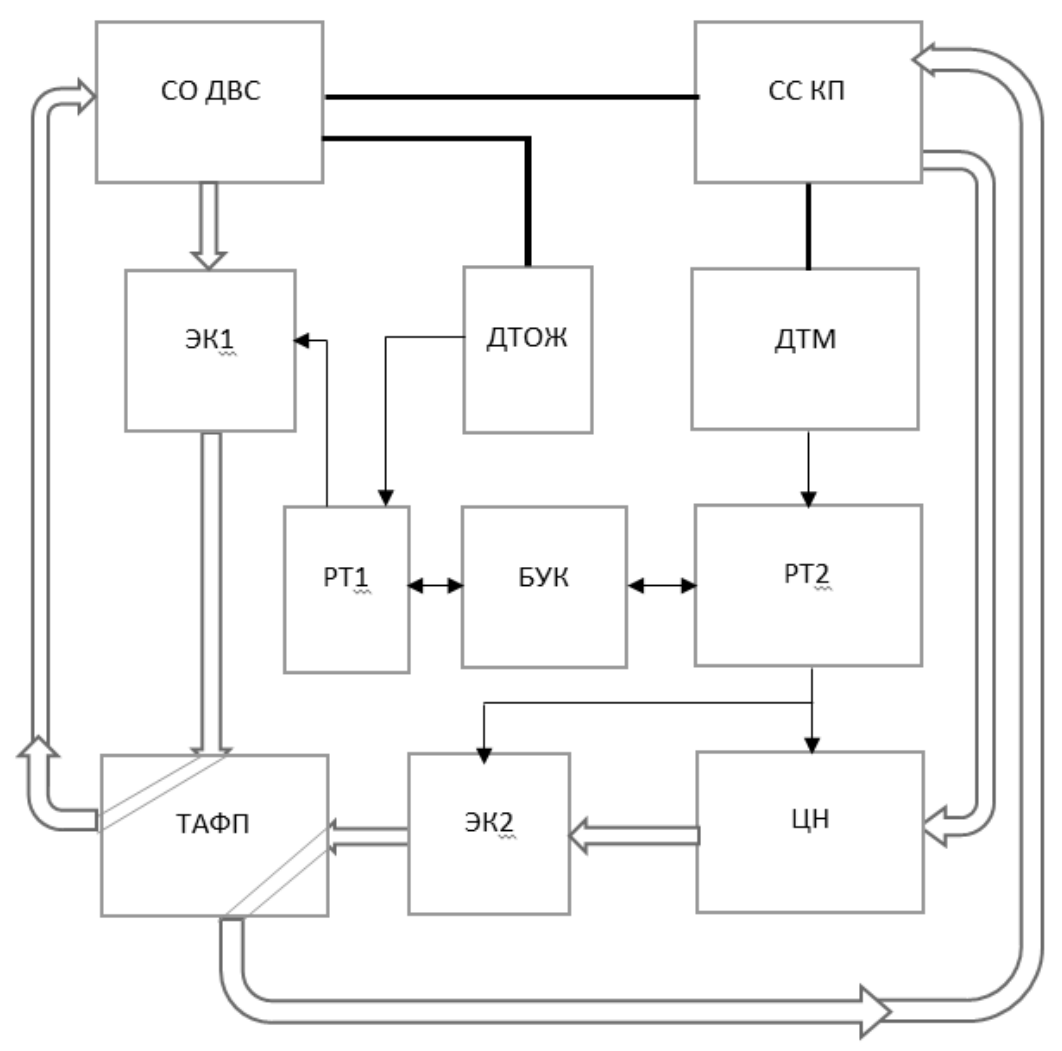

Puс. 2. Функциональная схема системы регулирования температуры масла в КП автомобиля КамАЗ с ТАФП:

БУК - Блок управления контроля; СО ДВС - Система охлаждения ДВС;

ТАФП - Тепловой аккумулятор фразового перехода; СС КП - Система смазки коробки передач; ДТМ - Датчик температуры масла в КП; РТ1, РТ2 - Реле температуры; ЦН - Циркуляционный насос; ЭК1, ЭК2 - Электромагнитные клапаны; дТОЖ - штатный датчик температуры охлаждающей жидкости автомобиля. - - Механическая связь; - Гидравлическая связь; - Электрическая связь

ние твердого теплоаккумулирующего материала). При снижении $t_{\text {ож }}<+85^{\circ} \mathrm{C}$ (при остановках и стоянках автомобиля) РТ1 закроет ЭК1 и циркуляция ОЖ прекратится. ТАФП перейдет в режим хранения заряда теплоты.

Эффективная теплоизоляция корпуса ТАФП минимизирует потери за счет теплопередачи через стенки ТАФП в окружающую среду, обеспечивая жидкое состояние ТАМ за время ночной стоянки при температуре окружающего воздуха до $-30 \ldots-40^{\circ} \mathrm{C}$.

При работе автомобиля в зимний период водитель устанавливает переключатель режимов работы на передней панели блока управления и контроля (БУК) в положение «Зима», при этом реле температуры масла (РT2) настраивается на включение при температуре масла выше $-15^{\circ} \mathrm{C}$, выключение - при $+78^{\circ} \mathrm{C}$.

Во время предпусковой подготовки агрегатов автомобиля КамАЗ в зимний период водитель включает штатный подогреватель ОЖ, который подогревает ДВС до + $55^{\circ} \mathrm{C}$. Часть тепла, за счет теплопроводности материала корпусов ДВС и трансмиссии, передается на КП и подогревает масло в ней. При прогреве масла до $-15^{\circ} \mathrm{C}$ по сигналу датчика температуры масла (ДТМ) включится РТ2 и подаст команду на включение электромагнитного клапана ЭК2, циркуляционного насоса (ЦН), а также контрольной лампочки «Разрядка» ТАФП. Это обеспечит забор холодного масла из нижней части картера КП, его прокачку через ТАФП и подачу подогретого масла в верхнюю часть картера КП (рис. 1).

Отбор тепла холодным маслом от ТАМ сопровождается его затвердеванием и разрядкой ТАФП до момента достижения температуры масла в КП + $78^{\circ} \mathrm{C}$. При данной температуре сработает РТ2 и выключит ЭК2 и ЦН, а на БУ погаснет контрольная лампочка «Разрядка» ТАФП. При снижении температуры масла до $+70{ }^{\circ} \mathrm{C}$ РТ2 снова включит ЭК2 и ЦН и подогреет масло до $+78{ }^{\circ} \mathrm{C}$, обеспечивая тем самым автоматическое поддержание рационального температурного режима КП. 
В летний период эксплуатации водитель устанавливает переключатель режимов работы в положение «Лето», при этом система включается сразу после пуска ДВС и работает аналогично, обеспечивая быстрый прогрев и поддержание рационального температурного режима КП.

\section{Заключение}

Предложены способ и система обеспечения рационального температурного режима коробки передач автомобиля КамАЗ с использованием теплового аккумулятора фазового перехода. Проведен расчет объема теплоаккумулирующего материала, необходимого для подогрева трансмисси- онного масла коробки передач автомобиля КамАЗ до рациональной температуры в условиях зимней эксплуатации. Разработаны гидравлическая и функциональная схемы системы регулирования температуры масла в коробке передач автомобиля КамАЗ с тепловым аккумулятором фазового перехода. Применение системы обеспечит быстрый выход на рациональный температурный режим коробки передач автомобиля и его стабилизацию как в зимнее, так и в летнее время года и, тем самым, снизит износ деталей, механические потери в коробке передач, расход топлива автомобилем.

\section{Лumepamypa}

1. Теплофизические свойства фазопереходных теплоаккумулирующих материалов, применяемых в строительстве / И. О. Аймбетова, У. С. Сулейменов, М. А. Камбаров [и др.] // Успехи современного естествознания. - 2018. - № 12-1. - С. 9-13. [Электронный ресурc]. URL: http://natural-sciences. ru/ru/article/view? id=36966 / (дата обращения: 09.09.2019).

2. Виленкин, А. В. Масла для шестереночных передач / А. В. Виленкин. - Москва: Химия, 1982. - 248 с.

3. Особенности эксплуатации трансмиссий грузовых автомобилей при низких температурах окружающего воздуха / И. Х. Девликамов, С. О. Андронов, Д. А. Близнов [и др.] // Инновационные идеи молодых исследователей для агропромышленного комплекса России: сборник статей Международной научно-практической конференции молодых ученых. Том III / Пензенский ГАУ. - Пенза: РИО ПГАУ, 2018. - С. 10-12.

4. Способы и средства тепловой подготовки агрегатов транспортных машин / И. Х. Девликамов, С. О. Андронов, А. А. Орехов [и др.] // Инженерная наука в АПК: проблемы, решения, перспективы: сборник материалов Всероссийской научно-практической конференции, посвящённой 65-летию инженерного факультета. - Пенза: РИО ПГАУ, 2017. - С. 9-12.

5. Дружинин, П. В. Предпусковая подготовка двигателей внутреннего сгорания при технической эксплуатации транспортных машин / П. В. Дружинин, А. А. Коричев, И. А. Косенков // Технико-технологические проблемы сервиса. - 2009. - № 4(10). - С. 7-12.

6. Жалнин, Д. В. Анализ конструкций устройств для тепловой подготовки двигателей автомобилей / Д. В. Жалнин // Вклад молодых ученых в инновационное развитие АПК России: сборник материалов Всероссийской научно-практической конференции. Том 2. - Пенза: РИО ПГСХА, 2014. - C. 203-207.

7. Жалнин, Д. В. Тепловые аккумуляторы фазового перехода для тепловой подготовки агрегатов автомобилей / Д. В. Жалнин, С. А. Матюшин // Вклад молодых ученых в инновационное развитие АПК России: сборник материалов Всероссийской научно-практической конференции. Пенза: РИО ПГСХА, 2012. - С. 211-213.

8. Итинская, Н.И. Топливо, масла и технические жидкости: справочник / Н. И. Итинская, Н. А. Кузнецов. - 2-е изд., перераб. и доп. - Москва: Агропромиздат, 1989. - 304 с.

9. Курносов, А. Ф. Подогрев механической коробки передач транспортных средств сельскохозяйственного назначения в условиях Сибири: диссертация на соискание ученой степени кандидата технических наук / А. Ф. Курносов. - Новосибирск, 2016. - 148 с.

10. Кутлин, А. А. Исследование влияния режима движения автомобилей на температуру их основных агрегатов и расход топлива в зимних условиях эксплуатации: автореферат диссертации на соискание ученой степени кандидата технических наук / А. А. Кутлин. - Киев, 1981. - 20 с.

11. Патент РФ № 2187049, МПК F 24 Н 7/00. Тепловой аккумулятор фразового перехода: опубл. 10.08.2002 / В. В. Шульгин, С. Д. Гулин, Г. И. Никифоров [и др.].

12. Патент РФ № 2215948, МПК F 24 H 7/00. Аккумулятор теплоты: опубл. 10.03.2003 / А. С. Гуртов, Г. Н. Мирошник, В. И. Михеев [и др.].

13. Патент РФ № 65190, МПК F 24 Н 7/00. Тепловой аккумулятор фразового перехода. Бюл. № 21: опубл. 27.07.2007 / М. В. Чушкин, И. А. Спицын, А. А. Орехов.

4. Спицын, И. А. Тепловой аккумулятор фазового перехода / И. А. Спицын, А. А. Орехов, М. В. Чушкин // Вестник ФГОУ ВПО МГАУ - 2008. - № 2. - С. 52-53.

15. Теплотехника: учебник для вузов. / В. Н. Луканин, М. Г. Шатров, Г. М. Камфер [и др.]; Под ред. В. Н. Луканина. - 3-е изд., испр. - Москва: Высш. шк., 2002. - 671 с.: ил.

16. Терморегулирование топливно-смазочных материалов в системах мобильных машин / под ред. П. А. Власова, А. П. Уханова, И. А. Спицына. - Пенза: РИО ПГСХА, 2001. - 140 с. 
17. Чарков, С. Т. Исследование изнашивания агрегатов трансмиссии автомобилей в зимних условиях эксплуатации: автореферат диссертации на соискание ученой степени кандидата технических наук / С. Т. Чарков. - Киев, 1980. - 17 с.

8. Проблема зимней эксплуатации автобусов разрешена / В. В. Шульгин, С. Д. Гулин, С. А. Яковлев [и др.] // Автомобильная промышленность. - 1998. - № 1. - С. 21-23.

19. Holzer, H. Das Kraftfahrzeug im Warmlauf / H. Holzer, P. Lenz. - Wärmemanagement des Kraftfahrzeugs II, 2000.

20. Rylyakin, E. G. Definition of Engine Capacity Losses on Resistance Overcoming in Transmission and a Hydraulic Actuator / E. G. Rylyakin // Contemporary Engineering Sciences. - 2017. - Vol. 10. - No. 8. - P. 353-357.

21. Salentine, C. G. Long-Term, Heavy-Duty Field Test Comparison of Four GL-5 Gear Lubricants / C. G. Salentine // SAE Technical Paper Ser. - 1990. - № 900811. - P. 1-20.

UDC $629.33-585$

DOI: $10.36461 /$ NP.2019.52.3.020

\title{
PROVIDING RATIONAL TEMPERATURE REGIME OF A KAMAZ CAR GEARBOX USED IN AGRICULTURE
}

\author{
A. A. Orekhov, Candidate of Technical sciences, assistant-professor; S. V. Timokhin, \\ Doctor of Technical sciences, professor; I. A. Spitsyn Doctor of Technical sciences, professor; \\ K. Z. Kuhmazov, Doctor of Technical sciences, professor
}

Federal State Budgetary Educational Institution of Higher Education «Penza State Agrarian University», Russia, t. 8 (8412) 62-85-79, e-mail: orehov.a.a@pgau.ru

The paper discusses the features of operation of cars at low ambient temperatures, as well as existing methods and means of heat treatment of their units. If the issues of thermal preparation and maintaining a rational temperature regime of automobile internal combustion engines are largely resolved, then for the units of their transmissions they require further development. The application of heat accumulators for the thermal preparation of automobile units is analyzed. A method and system for ensuring a rational temperature regime of a KamAZ car gearbox using a phase transition heat accumulator is proposed. The purpose and objectives of research are formulated. The calculation of the volume of heat-accumulating material necessary for heating the gear oil of a KamAZ car gearbox to a rational temperature in winter conditions has been carried out. A hydraulic and functional diagram of the oil temperature control system in a KamAZ car gearbox with a phase-transfer heat accumulator has been developed, the use of which will provide quick access to the rational temperature regime of the car gearbox and its stabilization in both winter and summer seasons and, thereby, reduce wear of parts, mechanical losses in the gearbox, fuel consumption by the car.

Key words: thermal preparation, unit, automobile, transmission, gearbox, ambient temperature, power loss, phase transition heat accumulator, wear rate.

References

1. Thermophysical properties of phase-transition heat-accumulating materials used in construction / I. O. Aimbetova, U. S. Suleimenov, M. A. Kambarov [et al.] // Successes in modern science. - 2018. No. 12-1. - p. 9-13. [Electronic resource]. URL: http://natural-sciences. ru/ru/article/view? id=36966/ (accessed: 09.09.2019).

2. Vilenkin, A. V. Oils for gears / A. V. Vilenkin. - Moscow: Chemistry, 1982.- 248 p.

3. Features of the operation of transmissions of trucks at low ambient temperatures / I. Kh. Devlikamov, S. O. Andronov, D. A. Bliznov [et al.] // Innovative ideas of young researchers for the agroindustrial complex of Russia: a collection of articles of the International scientific and practical conference of young scientists. Volume III / Penza SAU. - Penza: RIO PSAU, 2018.-- p. 10-12.

4. Methods and means of thermal preparation of aggregates of transport vehicles / I. Kh. Devlikamov, S. O. Andronov, A. A. Orekhov [et al.] // Engineering science in the agro-industrial complex: problems, solutions, prospects: a collection of materials of the All-Russian Scientific and Practical Conference dedicated to the 65th anniversary of the Faculty of Engineering. - Penza: RIO PGAU, 2017. - P. 9-12.

5. Druzhinin, P. V. Pre-launch preparation of internal combustion engines during the technical operation of transport vehicles / P. V. Druzhinin, A. A. Korichev, I. A. Kosenkov // Technicotehnologicheskie problemy servisa. - 2009. - No. 4 (10). - p. 7-12.

6 . Zhalnin, D. V. Analysis of the design of devices for thermal preparation of car engines / D. V. Zhalnin // The contribution of young scientists to the innovative development of the agroindustrial complex of Russia: a collection of materials of the All-Russian Scientific and Practical Conference. Volume 2. - Penza: RIO PSAA, 2014. - P. 203-207. 
7. Zhalnin, D. V. Phase transition heat accumulators for heat treatment of automobile units / D. V. Zhalnin, S. A. Matyushin // The contribution of young scientists to the innovative development of the agro-industrial complex of Russia: a collection of materials of the All-Russian Scientific and Practical Conference. - Penza: RIO PSAA, 2012.-- p. 211-213.

8. Itinskaya, N. I. Fuel, oils and technical fluids: reference book / N. I. Itinskaya, N. A. Kuznetsov. 2nd ed., revised and add. - Moscow: Agropromizdat, 1989. - 304 p.

9. Kurnosov, A. F. Heatup of mechanical gearboxes for agricultural vehicles in Siberia: the dissertation for the degree of candidate of technical sciences / A. F. Kurnosov. - Novosibirsk, 2016.-- 148 p.

10. Kutlin, A. A. Investigation of the influence of the mode of movement of cars on the temperature of their main units and fuel consumption in winter conditions of operation: abstract of the dissertation for the degree of candidate of technical sciences / A. A. Kutlin. - Kiev, 1981. - 20 p.

11. RF patent No. 2187049, IPC F 24 H 7/00. Thermal battery phase transition: publ. 08/10/2002 / V. V. Shulgin, S. D. Gulin, G. I. Nikiforov [et al.].

12. RF patent No. 2215948, IPC F 24 H 7/00. Heat accumulator: publ. March 10, 2003 / A. S. Gurtov, G. N. Miroshnik, V. I. Mikheev [et al.].

13. RF patent No. 65190, IPC F 24 H 7/00. Phase transition heat accumulator. Bulletin No. 21: publ. July 27, 2007 / M. V. Chushkin, I. A. Spitsyn, A. A. Orekhov.

14. Spitsyn, I. A. Phase transition thermal battery / I. A. Spitsyn, A. A. Orekhov, M. V. Chushkin // Vestnik of FSEI HPE MSAU - 2008. - No. 2. - P. 52-53.

5. Heat engineering: a textbook for universities. / V. N. Lukanin, M. G. Shatrov, G. M. Camfer [et al.]; Ed. by V. N. Lucanin. - 3rd ed., Revised - Moscow: Higher school., 2002. - 671 p.

16. Thermal management of fuel and lubricants in systems of mobile machines / ed. by P. A. Vlasov, A. P. Ukhanov, I. A. Spitsyn. - Penza: RIO PSAA, 2001. - 140 p.

17. Charkov, S. T. Research of deterioration of transmission units of automobiles in winter operating conditions: abstract of dissertation for the degree of candidate of technical sciences / S. T. Charkov. Kiev, 1980. -17 p.

18. The problem of winter operation of buses is solved / V. V. Shulgin, S. D. Gulin, S. A. Yakovlev [et al.] // Avtomobilnaya promyshlennost. - 1998. - No. 1. - p. 21-23.

19. Holzer, H. Das Kraftfahrzeug im Warmlauf / H. Holzer, P. Lenz. - Wärmemanagement des Kraftfahrzeugs II, 2000.

20. Rylyakin, E. G. Definition of Engine Capacity Losses on Resistance Overcoming in Transmission and a Hydraulic Actuator / E. G. Rylyakin // Contemporary Engineering Sciences. - 2017. - Vol. 10. - No. 8. - P. 353-357.

21. Salentine, C. G. Long-Term, Heavy-Duty Field Test Comparison of Four GL-5 Gear Lubricants / C. G. Salentine // SAE Technical Paper Ser. - 1990. - № 900811. - P. 1-20. 